\title{
Series Compensation to Increase Power Flow: a Case Study on the Irish Transmission System
}

\author{
Aidan Heffernan \\ Technological University Dublin \\ Jane Courtney \\ Technological University Dublin, jane.courtney@tudublin.ie
}

Follow this and additional works at: https://arrow.tudublin.ie/engscheleart

Part of the Electrical and Electronics Commons, and the Power and Energy Commons

\section{Recommended Citation \\ Heffernan, A. \& Courtney, J. (2019).Series compensation to increase power flow: a case study on the Irish Transmission System. 54th International Universities Power Engineering Conference (UPEC), Bucharest, Romania, 2019, pp. 1-5. doi: 10.1109/UPEC.2019.8893636.}

This Conference Paper is brought to you for free and open access by the School of Electrical and Electronic Engineering at ARROW@TU Dublin. It has been accepted for inclusion in Conference papers by an authorized administrator of ARROW@TU Dublin. For more information, please contact arrow.admin@tudublin.ie, aisling.coyne@tudublin.ie,gerard.connolly@tudublin.ie.

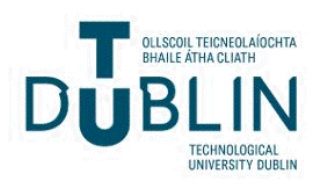




\section{Series Compensation to Increase Power Flow: A Case Study on the Irish Transmission System}

\author{
Aidan Heffernan \\ School of Electrical and Electronic Engineering \\ Technological University Dublin, City Campus \\ Dublin, Ireland \\ Aidan.heffernan@student.dit.ie
}

\author{
Dr. Jane Courtney \\ School of Electrical and Electronic Engineering \\ Technological University Dublin, City Campus \\ Dublin, Ireland \\ Jane.Courtney@dit.ie
}

\begin{abstract}
Ireland presents an interesting case study for transmission network strengthening. The majority of load in the country is located at the nation's capital, Dublin, in the East, while most of the new conventional generation and renewable generation are found in the South-West. Power is transferred between the two via a $400 \mathrm{kV}$ network. This leads to large crosscountry power flows. This power distribution disparity is due to increase. A large thermal generating station which is connected to the $400 \mathrm{kV}$ system in the West, will close by 2025 . This generation will be replaced partially with wind generation in the South West, which is connected at $110 \mathrm{kV}$ and $220 \mathrm{kV}$. This can cause power flow to avoid the $400 \mathrm{kV}$ network, leading to less efficiency, overloading and other issues associated with power flow on lower voltage networks.
\end{abstract}

In this paper, the application of series compensation on the $400 \mathrm{kV}$ transmission network in Ireland for increasing power transfer capability is investigated and a viable solution is found. The lower voltage network is modelled to investigate the effects of $400 \mathrm{kV}$ series compensation on the rest of the network. With our series compensation solution on the $400 \mathrm{kV}$ network, power flows are successfully reduced on the $110 \mathrm{kV}$ network as the lower reactance of the $400 \mathrm{kV}$ network now attracts power to flow through the more stable and less lossy $400 \mathrm{kV}$ network.

\section{Index Terms--FACTS, D-FACTS, Series Compensation}

\section{INTRODUCTION}

The characteristics of a power system evolve over time, as load grows, and generation is added. If the transmission facilities are not upgraded sufficiently, the power system becomes vulnerable to steady-state and transient stability problems, as stability margins become narrower [1]. A common solution for increasing transmission capacity has been to construct new transmission lines. Currently, there is pressure to increase power flow in existing right of ways using existing infrastructure as far as possible due to the increasing rejection of new electrical installations by the public [2]. This is where transmission line compensation becomes essential. Transmission line compensation means the existing lines are regulated. The sending end and receiving end voltages are maintained constant for all loads by using capacitors, inductors or electronic devices.
Series compensation is widely used worldwide as a method for increasing the power transfer capability on long transmission lines. There are currently no applications of series compensation in Ireland.

Eirgrid is the Transmission System Operator in Ireland. The Eirgrid Needs Report which was compiled in July 2017 [19] identifies a number of Tomorrow's Energy Scenarios. Two significant drivers that highlight the need to upgrade the transmission network by 2025 are [19]:

1. Increased demand on the East coast - There is an expected demand increase in the order of $900 \mathrm{MW}$ due the connection of data centres. This is based on executed and offered connection agreements in the East of the country.

2. Integration of generation in the South and South West Significant levels of new renewable generation have connected or are in the process of connecting to the grid in the South and South West. This is also where the newer and most cost-effective conventional generation units are located.

The two drivers above introduce the need for large crosscountry power flows on the existing transmission system from the West to the East coast [19]. Figure 1 is a map of the transmission network in Ireland illustrating the main generation and load centres.

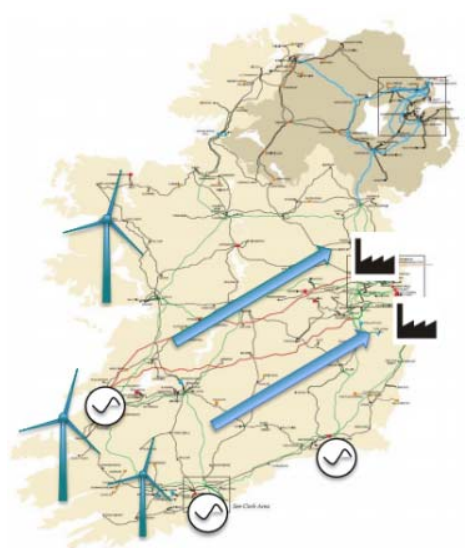

Figure 1 - Map of Ireland showing main generation and load centres 
Although series compensation is mature technology, it has never before been used in Ireland. Ireland's largest generating station is the $900 \mathrm{MW}$ Moneypoint plant which uses coal to generate electricity. This plant, which is located in the West of the country, is due to reach the end of its operating life in 2025. As there is an expected demand increase of $900 \mathrm{MW}$ in the East, this loss of $900 \mathrm{MW}$ generating capacity would have the net effect of a $1,800 \mathrm{MW}$ deficit in generated power. Therefore, new renewable generation in the West of the country will play a crucial role in supplying the load in the East of the country in the near future. This is why new and innovative methods for improving transmission capability between the West and East of Ireland are crucial.

\section{RELATED WORK}

\section{A. Options for Increasing Transmission Line Power Transfer}

Some typical options for increasing transmission line power transfer capability are [2][4][5]:

- Build additional transmission lines and cable circuits.

- Increase existing transmission line voltage (for example from $220 \mathrm{kV}$ to $400 \mathrm{kV}$ ).

- Increase current density using high tension low sag conductors (HTLS).

- Use AC lines to transmit DC power (using AC-DC and DC-AC converters).

- Dynamic rating of transmission lines.

- Series or shunt compensation (fixed and/or power electronic methods)

\section{B. What is Series Compensation?}

Series compensation has been used to improve power transfer in long-distance transmission systems worldwide [6]. A series compensator (usually a capacitor) is typically installed in series with a transmission line to increase or decrease the effective reactive impedance of the line, allowing control of real power flow between the two buses [3].

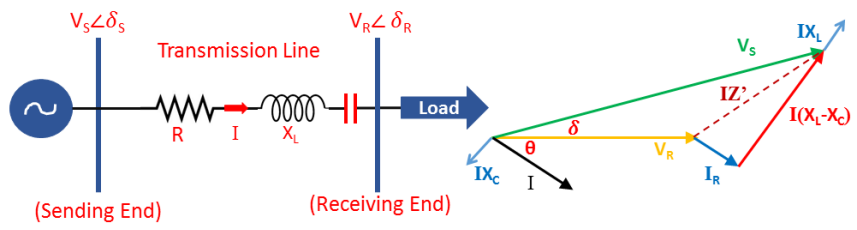

Figure 1 - Series compensation on a transmission line

The received power is increased depending on the value of capacitive reactance $(\mathrm{Xc})$ added in series with the transmission line as per the below equation:

$$
P_{R}=\frac{V_{S} V_{R}}{X_{L}-X_{C}} \sin \delta
$$

\section{Types of Series Compensation}

Fixed Series Compensation (FSC):

This is the simplest and most cost-effective type of series compensation and is provided by Fixed Series Capacitors (FSC) [7]. The aim is to cancel part of the reactance of the line by means of series capacitors [8].

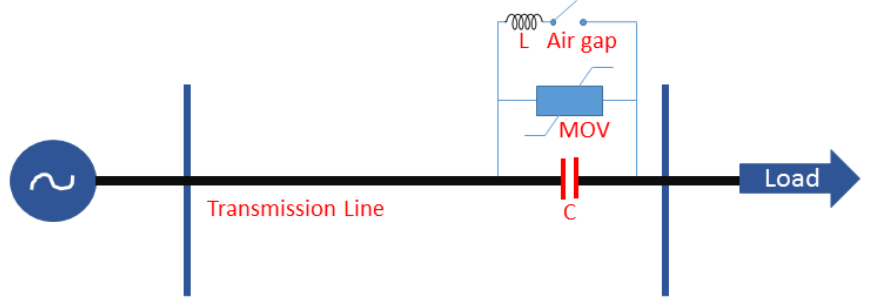

Figure 2. Fixed series compensation

Under normal operation, a zinc oxide varistor (MOV) of nonlinear type presents a high resistance [9]. When the voltage across the capacitor exceeds a protective level, the resistance of the varistor becomes very low and it conducts. It therefore diverts part of the fault current away from the capacitor. Since there is an upper limit for energy dissipation in the MOV, for its protection there is special circuitry which calculates the energy dissipated by the varistor and triggers the air gap to divert away from the series compensation unit [20]. There is a damping inductor (L) for the purpose of limiting the discharge current from the capacitor [10].

Variable Series Compensation (VSC):

With the advent of power electronic devices like the Thyristor and associated controls (Flexible AC Transmission Systems FACTS), the usefulness of controlled series compensation has been widened [11]. Thyristor Controlled Series Capacitor (TCSC) is a FACTS device connected in series on transmission lines to control the dynamic power flow and enhance the power quality [4]. With a TCSC, it is possible to vary the degree of compensation rapidly, limited only by the speed of response of the electronic scheme used [11].

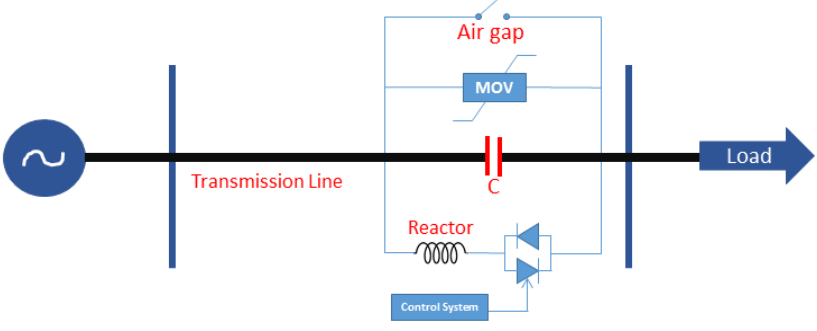

Figure 3. Variable series compensation

TCSC comprises of a series capacitor in parallel with a Thyristor Controlled Reactor (TCR). By varying the firing angle of the thyristor (to make the switch on/off), the TCSC can optimise the degree of compensation over a wide range under various network conditions. Varying the firing angle of the TCR is used to control the capacitive reactance of the TCSC [4][12]. Operationally, when the thyristors are firing, the TCR branch circulates current pulses, which add in phase 
with the line current. This boosts the capacitive voltage beyond the level that would be obtained by the line current alone [11]. Like with fixed series compensation, the TCSC is protected by a MOV.

\section{Positive effects of Series Compensation}

There are many positive effects of series compensation [11][13][14], including:

- Increases the loadability of long lines up to their thermal limits.

- Acts as a self-regulating device for better voltage regulation.

- Reduces overall transmission losses.

- Improves network stability - both voltage and angular.

- Enables balanced power sharing between parallel lines so as to achieve best possible utilisation of transmission lines.

\section{E. Negative effects of Series Compensation}

Some negative effects of series compensation [15][16][17] include:

- Sub-synchronous resonance possibility.

- Protection over reach and under reach issues.

\section{F. Series Compensation Example}

A successful example of series compensation is in Finland. Two series capacitors, rated at 369 Mvar each, were installed on Fingrid's $400 \mathrm{kV}$ grid to strengthen the power transmission capacity in northern Finland and to assure power system security. The series capacitors both went on line in 2009 [20]. These series capacitors add transmission capacity towards neighbouring Sweden by some $200 \mathrm{MW}$, using the existing network. They are needed to meet the rising market demand on power transmission between northern Finland and Sweden and also internally in Finland. Series capacitors enabled added transmission capacity on existing power lines and helped maintain grid stability in the Finnish power system. The series capacitors were designed to compensate $70 \%$ of the existing lines reactance. The result of this 2009 installation of two FSC's is strengthened power transmission capacity and assured power system security in northern Finland.

\section{SERIES COMPENSATION IN IRELAND}

The area of network that was considered for this study is highlighted in Figure 4. The two $400 \mathrm{kV}$ circuits are illustrated in red, the $220 \mathrm{kV}$ in green and the $110 \mathrm{kV}$ in black.

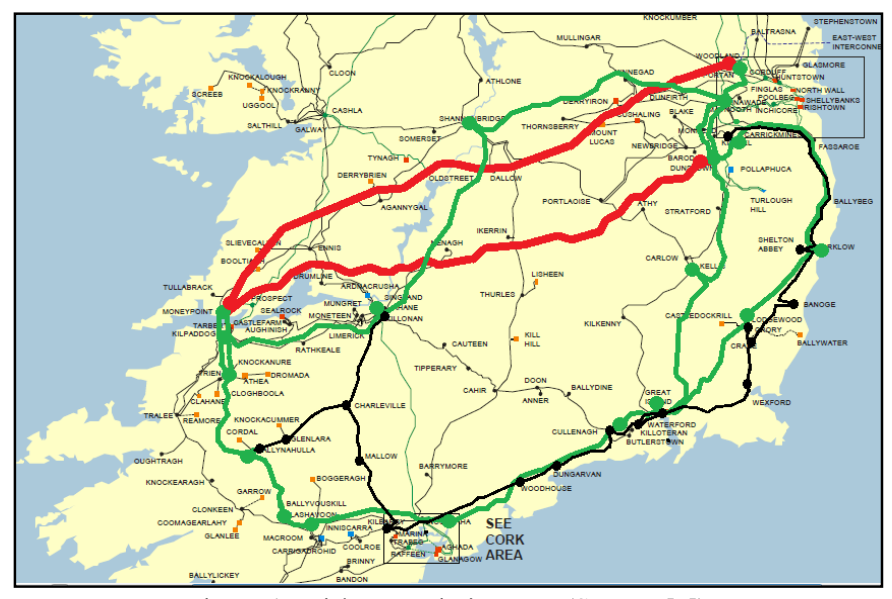

Figure 4 - Irish transmission map (Source: [7])

The transmission map from Figure 4 is translated into an electrical equivalent Single Line Diagram (SLD) in Figure 5.

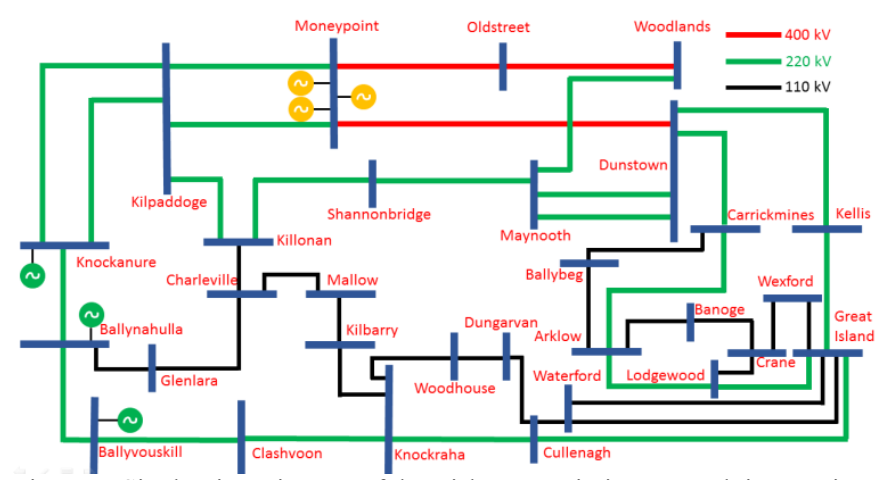

Figure 5. Single Line Diagram of the Irish Transmission network in question

The largest generating station in Ireland, Moneypoint (900 MW) connects directly to the $400 \mathrm{kV}$ network in the West of the country. This model analyses the network when $50 \%$ of the generation output of Moneypoint is replaced by wind generation in the South-West of Ireland. The four cases in Table 1 are analysed using PSS®E software.

Table 1. Four cases analysed

\begin{tabular}{|c|c|c|c|c|c|}
\hline Case & $\begin{array}{c}\text { Series } \\
\text { Compensation }\end{array}$ & $\begin{array}{c}\text { Moneypoint } \\
\text { (MW) }\end{array}$ & $\begin{array}{c}\text { Wind } \\
\text { (MW) }\end{array}$ & $\begin{array}{c}\text { Combined } \\
\text { (MW) }\end{array}$ & $\begin{array}{c}\text { Moneypoint } \\
\text { Reduction }\end{array}$ \\
\hline $\mathbf{1}$ & No & 843 & 146 & 989 & 0 \\
\hline $\mathbf{2}$ & $70 \%$ & 843 & 146 & 989 & 0 \\
\hline $\mathbf{3}$ & No & 422 & 567 & 989 & $50 \%$ \\
\hline $\mathbf{4}$ & $70 \%$ & 422 & 567 & 989 & $50 \%$ \\
\hline
\end{tabular}

- Case 1 - the current network configuration is analysed as a base case.

- Case $2-70 \%$ series compensation is applied to both of the $400 \mathrm{kV}$ circuits.

- Case 3 - half of the capacity of Moneypoint generating station is replaced by wind generation in the South West connected to the $110 \mathrm{kV}$ and $220 \mathrm{kV}$ network. There is no series compensation on the network.

- Case 4 - half of the capacity of Moneypoint generating station is replaced by wind generation in the South West 
connected to the $110 \mathrm{kV}$ and $220 \mathrm{kV}$ network. There is $70 \%$ series compensation on the $400 \mathrm{kV}$ network.

\section{RESULTS}

When half of the capacity of Moneypoint is replaced by wind generation on the South West, the power flow on the $400 \mathrm{kV}$ network is reduced. This is undesirable as losses are the smallest on the $400 \mathrm{kV}$ network. As generation must be matched with demand at all times, the power that previously flowed on the $400 \mathrm{kV}$ network now flows on other lower voltage sections of the network. This equates to higher losses. When series compensation was added to the $400 \mathrm{kV}$ network, power flows on the $400 \mathrm{kV}$ network increased to values similar to that when Moneypoint was supplying the full 843 MW to the network as evidenced in Figure 6.

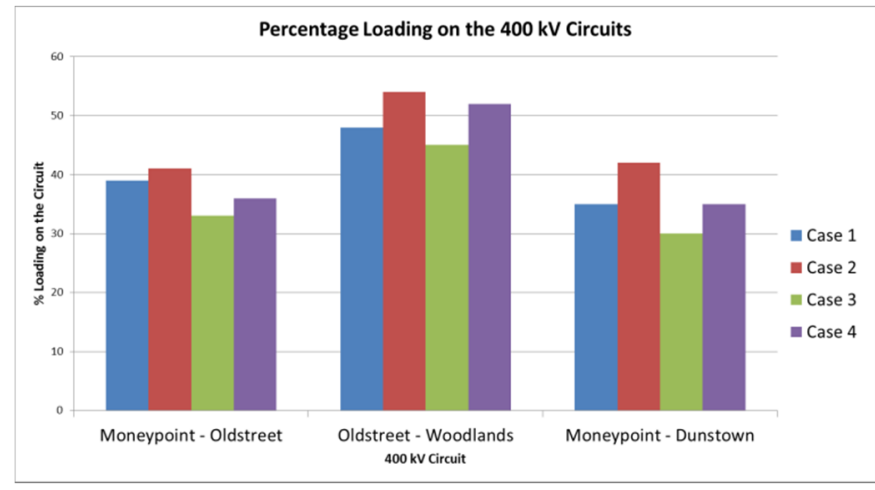

Figure 6 - Percentage loading on the $400 \mathrm{kV}$ circuits

In recent years, the $220 \mathrm{kV}$ grid in the South West of Ireland has been reinforced. This included the construction of three new $220 \mathrm{kV}$ substations; Knockanure, Ballynahulla and Ballyvouskill, along with the associated circuits connecting these substations to the new Moneypoint $220 \mathrm{kV}$ substation. Figure 7 shows that when $422 \mathrm{MW}$ of wind generation is connected to these three substations, the loadings on the $220 \mathrm{kV}$ network around the South West are substantially increased as shown in the dashed red box, as designed. The remainder of the $220 \mathrm{kV}$ network remains generally unchanged.

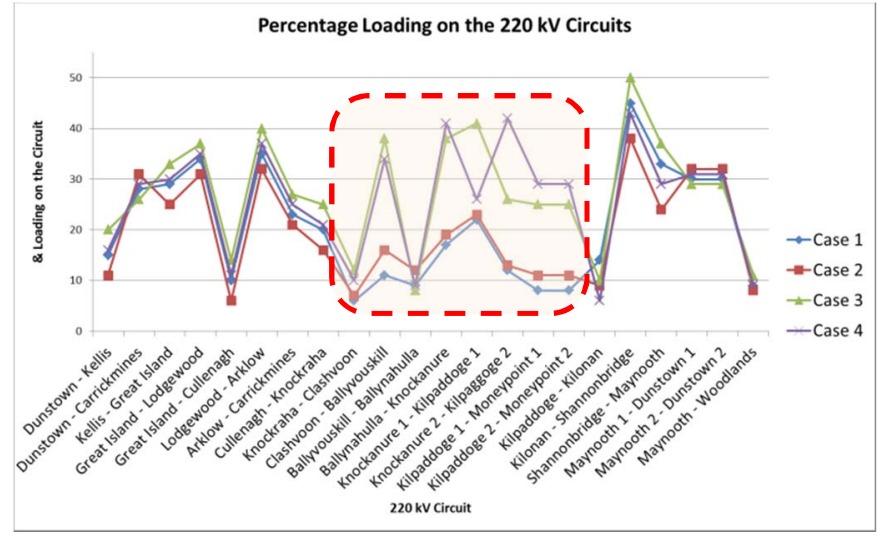

Figure 7 - Percentage loading on the $220 \mathrm{kV}$ circuits
In Figure 8 it is evident that in case three, with the addition of wind generation, the loadings on the $110 \mathrm{kV}$ network increase substantially. This is undesirable as the net system losses are higher and the $110 \mathrm{kV}$ network is not as reliable as the $400 \mathrm{kV}$ network. With the addition of series compensation to the $400 \mathrm{kV}$ network, the loadings on the $110 \mathrm{kV}$ lines reduce greatly. In fact, it can be seen that the loadings in case one, with Moneypoint generating $843 \mathrm{MW}$ and case four, $50 \%$ of Moneypoint coming from wind generation and series compensation applied to the $400 \mathrm{kV}$ network, the loadings on the $110 \mathrm{kV}$ network are almost identical.

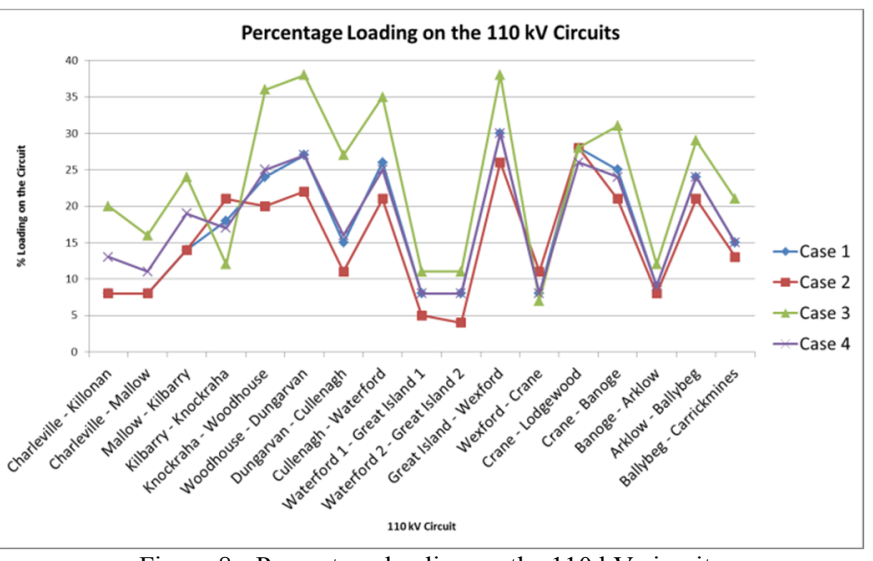

Figure 8 - Percentage loading on the $110 \mathrm{kV}$ circuits

\section{CONCLUSION}

The aim of this paper is to investigate the effects of series compensation on the transmission network in Ireland, in particular on the $400 \mathrm{kV}$ network. Electricity demand is growing in Ireland and there are $900 \mathrm{MW}$ of executed and offered connection agreements alone for connecting data centres to the grid in the greater Dublin area by 2025 .

Traditionally, the method for increasing power transfer capability in Ireland has been by building new transmission circuits. Worldwide, series compensation has been used to increase power transfer capability of long transmission lines, while exploiting the existing transmission lines and right of ways. Series compensation has never been deployed in Ireland.

A PSS ${ }^{\circ} E$ model was used to investigate the effects that installing series compensation on the $400 \mathrm{kV}$ network had on other areas of the network. The largest thermal generating plant in Ireland, Moneypoint directly connects to the $400 \mathrm{kV}$ network in the West. This simulation scaled back the output of Moneypoint by $50 \%$ and replaced it with equivalent wind generation in the South West of the country. Analysis showed that this caused increased power flows on the $110 \mathrm{kV}$ network, which is weaker and has higher losses than the $400 \mathrm{kV}$ network. Current will take the path of least resistance. When series compensation was added to the $400 \mathrm{kV}$ network, the power flow on the $110 \mathrm{kV}$ network decreased. This power instead travelled through the $400 \mathrm{kV}$ network because of its 
reduced reactance due to the application of series compensation.

This is the desired consequence, as the $400 \mathrm{KV}$ network is stronger, has higher MVA ratings and provides a direct connection from the West to the East of Ireland, unlike the $110 \mathrm{kV}$ network which connects through many nodes. Series compensation Enabled balanced power sharing between parallel lines so as to achieve best possible utilisation of transmission lines.

This paper has demonstrated the benefits that series compensation can bring to the Irish transmission system; increased power transfer capability while using existing assets, aiding the replacement of thermal generation with renewables, and increasing stability. This solution is applicable to other similar scenarios found on power systems throughout the world.

\section{REFERENCES}

[1] E. Acha, C. R. Fuertw-Esquivel, H. Ambriz-Perez, and C. AngelesCamacho, FACTS Modelling and Simulation in Power Networks. Wiley, 2004.

[2] I. Albizu, A. J. Mazon, and I. Zamora, "Methods for increasing the rating of overhead lines," in IEEE Power Tech, 2005, pp. 1-6.

[3] M. Baby and R. Thilepa, "Power Flow Control In a Transmission Line Using Unified Power Flow Controller," Int. J. Power Control Signal Comput., vol. 2, no. 1, pp. 38-44, 2014.

[4] B. Noor, M. Aamir Aman, M. Ali, S. Ahmad, and F. Wahab Karam, "Impact of Thyristor Controlled Series Capacitor on Voltage Profile of Transmission Lines using PSAT," IJACSA) Int. J. Adv. Comput. Sci. Appl., vol. 9, no. 2, 2018.

[5] D. Larruskain et al., "Power transmission capacity upgrade of overhead lines," $R E \& P Q J$, vol. 1, no. 4, pp. 221-227, 2006.

[6] J. O. Eyenubo, "Transmission System for Series-Shunt Compensated Network using Matlab/Simulink," ATBU J. Sci. Technol. Educ., vol. 4, no. 3, p. 2016, 2016.

[7] Siemens, "Series Compensation (SC)," 2017. [Online]. Available: https://www.energy.siemens.com/ru/en/power-transmission/facts/seriescompensation/\#content=Fixed Series Capacitor (FSC). [Accessed: 26Jan-2019].

[8] A. Nekoubin, "Simulation of Series Compensated Transmission Lined Protected with Mov," Int. J. Electr. Comput. Eng., vol. 5, no. 1, pp. 1385-1389, 2011.

[9] J. Miller, M. Brunet-Watson, and J. Leighfield, "Review of Series Compensation for Transmission Lines," 2014.

[10] L. Ängquist, "Synchronous Voltage Reversal Control of Thyristor Controlled Series Capacitor," Royal Institute of Technology, 2002.

[11] R. N. Nayak, Y. K. Sehgal, and S. Sen, "Series Compensation on 400 kV Transmission Line - A Few Design Aspects," in National Power systems Conference, 2004, pp. 206-211.

[12] C. U. Shankar, R. Thottungal, and C. S. Priya, "Enhancement of transient stability and dynamic power flow control using Thyristor Controlled Series Capacitor," Int. J. Res. Appl. Sci. Eng. Technol., vol. 3, no. 1, pp. 1-6, Jan. 2015.

[13] D. Korot, P. Marken, and L. Bock, "The Next Fifty Years of Series Capacitors - And the Last Eighty-six," 2014.

[14] ALSTOM, "Fixed Series Compensation - Fast Product Details," 2014.

[15] K. Kabiri, "Analysis and Control of Sunsynchronous Resonance in the Presence of Thyristor Controlled Series Compensation," University of British Columbia, 2004.

[16] G. V Rajasekhar and G. Sarma, "Analysis of Sunsynchronous Resonance Effect in Series Compensated Line with Booster Transformer," Int. J. Electr. Electron. Eng., vol. 1, no. 4, pp. 22315284, 2012.
[17] E. Fossen, "Mitigation of Subsynchronous Resonance with Thyristor Controlled Series Compensation in the Great Britain Power Network," Norwegian University of Science and Technology, 2016.

[18] Eirgrid \& Soni, "All-Island Ten-Year Transmission Forecast Statement 2017," Dublin, 2017.

[19] Eirgrid, "Needs Report - Capital Project 966," Dublin, 2017.

[20] ABB, "Series Capacitors for increased power transmission capacity in the Finnish $400 \mathrm{kV}$ grid," Finland, 2009.

[21] ESB, "Moneypoint | ESB Archives," 2016. [Online]. Available: https://esbarchives.ie/portfolio/moneypoint/. [Accessed: 17-Feb-2019].

[22] "Government urged to reveal Moneypoint plan," The Clare Champion, 17-Feb-2019. 